\title{
RESEARCH
}

Open Access

\section{Preoperative plasma D-dimer independently predicts survival in patients with pancreatic ductal adenocarcinoma undergoing radical resection}

\author{
Haoda Chen ${ }^{\dagger}$, Fanlu Li ${ }^{\dagger}$, Siyi Zou ${ }^{\dagger}$, Junjie Xie, Jun Zhang, Xiaxing Deng, Hao Chen ${ }^{*}$ and Baiyong Shen ${ }^{*}$
}

\begin{abstract}
Background: Elevated plasma D-dimer levels have been reported as an unfavorable prognostic indicator in many solid tumors. However, there are limited relevant studies in pancreatic cancer patients following radical surgery, and the clinical significance remains controversial. The aim of this study was to investigate the clinical and prognostic significance of preoperative plasma D-dimer in patients with pancreatic ductal adenocarcinoma (PDAC) undergoing resection.
\end{abstract}

Methods: A retrospective analysis was performed on all patients who consecutively underwent radical surgery for PDAC by laparotomy or robotic surgery from December 2011 to December 2018. Baseline clinicopathologic characteristics, preoperative laboratory parameters, and follow-up information were collected. Univariate and multivariate analyses were performed to analyze the prognostic value of preoperative plasma D-dimer.

Results: Among 1351 patients, elevated preoperative plasma D-dimer levels ( $\geq 0.55 \mathrm{ng} / \mathrm{mL}$ ) were found in 417 (30.9\%) patients. Three hundred twelve (23.09\%) underwent minimally invasive robotic pancreatectomy. The median overall survival (OS) of patients with elevated D-dimer levels was 6.3 months shorter than that of patients with normal D-dimer levels (15.0 months vs 21.3 months, $\mathrm{p}<0.001)$. Multivariate analysis showed that elevated D-dimer levels independently predicted poorer OS (hazard ratio, 1.33; 95\% confidence interval, 1.17-1.51, p < 0.001). Subgroup analysis demonstrated that D-dimer was a reliable prognostic factor in patients who underwent R0 resection. In addition, integration of D-dimer, carbohydrate antigen 19-9 (CA19-9), and NLR provided a better prognostic model for PDAC patients before operation.

Conclusion: An elevated preoperative plasma D-dimer level was a reliable independent prognostic factor for OS in patients with PDAC undergoing resection. Combination of D-dimer, CA19-9, and NLR can enhance the prognostic accuracy before operation.

Keywords: D-dimer, Pancreatic ductal adenocarcinoma (PDAC), Pancreatic surgery, Prognostic factors

\footnotetext{
* Correspondence: haochendr@126.com; shenby@shsmu.edu.cn

${ }^{+}$Haoda Chen, Fanlu Li, and Siyi Zou are co-first authors.

Department of General Surgery, Pancreatic Disease Center, Ruijin Hospital,

Shanghai Jiao Tong University School of Medicine, 197 Ruijin Er Road,

Shanghai 200025, China
}

C C The Author(s). 2021 Open Access This article is licensed under a Creative Commons Attribution 4.0 International License, which permits use, sharing, adaptation, distribution and reproduction in any medium or format, as long as you give appropriate credit to the original author(s) and the source, provide a link to the Creative Commons licence, and indicate if changes were made. The images or other third party material in this article are included in the article's Creative Commons licence, unless indicated otherwise in a credit line to the material. If material is not included in the article's Creative Commons licence and your intended use is not permitted by statutory regulation or exceeds the permitted use, you will need to obtain permission directly from the copyright holder. To view a copy of this licence, visit http://creativecommons.org/licenses/by/4.0/ The Creative Commons Public Domain Dedication waiver (http://creativecommons.org/publicdomain/zero/1.0/) applies to the data made available in this article, unless otherwise stated in a credit line to the data. 


\section{Introduction}

Pancreatic cancer, a highly aggressive malignancy, is the fourth leading cause of cancer-related deaths in developed countries, with an overall 5-year survival rate of 9\% [1]. Radical surgical resection remains the only treatment for long-term survival, but tumor recurrence occurs in almost $80 \%$ of patients [2]. In addition, patients with the same pathological staging and therapeutic procedure show differential prognosis after radical resection $[3,4]$. Although Ca19-9 has been widely used as an adverse prognostic biomarker in pancreatic cancer, approximately 6 to $22 \%$ of the population have no or low secretion of CA19-9 $[5,6]$. The heterogeneity of prognostic outcomes highlights the urgent need for a more robust biomarker for long-term oncological outcomes, which could help identify high-risk patients, decide individual therapeutic strategies, and facilitate close patient follow-up [4, 7-10].

Since Trousseau first described the relationship between cancer and thromboembolic disease in 1865 , activation of the coagulation system via hosttumor interactions has been found in almost all types of cancer [11-13]. In addition, the tumorinduced hypercoagulation state is not simply an epiphenomenon but is also intrinsically involved in enhanced tumor growth, angiogenesis, metastasis, and the systemic inflammatory response $[11,12,14]$. Ddimer is a soluble degradation product that results from the systematic degeneration of vascular thrombi by the fibrinolytic system [15]. The presence of D-dimer molecules is suggestive of intravascular coagulation since it can only be generated after thrombin formation and subsequent breakdown of cross-linked fibrin [16]. Therefore, plasma Ddimer levels are used routinely to monitor the risk of deep venous thrombosis (DVT), pulmonary embolism (PE), aortic dissection, and as an aid in the diagnosing disseminated intravascular coagulation (DIC) [15]. Recently, elevated plasma D-dimer levels have been reported to represent an unfavorable prognostic indicator in lung cancer, colorectal cancer, pancreatic cancer, and several other solid tumors [17]. Preoperative high level of D-dimer is also associated with occult hepatic metastases in patients with pancreatic head cancer [18].

However, there are limited relevant studies in pancreatic ductal adenocarcinoma (PDAC) patients following radical surgery, and no studies regarding the prognostic value of preoperative plasma D-dimer in PDAC patients treated with minimally invasive robotic surgery $[19,20]$. Therefore, the purpose of this study is to assess the predictive value of $\mathrm{D}$-dimer on postoperative overall survival in patients with PDAC in a high-volume pancreatic center.

\section{Methods}

\section{Patients}

A retrospective cohort analysis was performed on all patients who consecutively underwent radical surgery for PDAC by laparotomy or robotic surgery from December 2011 to December 2018 at the Department of General Surgery, Shanghai Ruijin Hospital. The inclusion and exclusion criteria were as follows: (1) pathologically proven PDAC; (2) complete clinicopathologic and follow-up data; (3) no evidence of distant metastasis or macroscopic residual tumors; (4) no preoperative antitumor treatment; (5) no history of other malignancies; (6) no acute inflammatory diseases; and (7) no anticoagulant therapy before the operation. This study was approved by the review board of Shanghai Ruijin Hospital (No. 2020-361). Informed consent was waived according the committee's regulations. Data has been reported in line with STROCSS 2019 criteria.

\section{Data collection}

Data were obtained from a prospectively maintained database and electronic medical records in the hospital. The clinical and demographic variables included age, sex, body mass index (BMI), platelet, albumin, neutrophil lymphocyte ratio (NLR), D-dimer, and serum carbohydrate antigen 19-9 (CA19-9) levels. All laboratory parameters were assayed during routine workups before surgery. Plasma D-dimer levels were measured by immunoturbidimetric assays. The normal reference value for plasma D-dimer and CA19-9 in our institution are below $0.55 \mathrm{ng} / \mathrm{mL}$ and $37 \mathrm{U} / \mathrm{mL}$, respectively.

The standard operative procedures and management strategies were described in our previous studies [21, 22]. The treatment details include preoperative biliary drainage, surgical approach (open/robotic), and the performance of major vessel resection (portal vein, superior mesenteric vein, celiac trunk, or common hepatic artery). The final pathological diagnosis was also documented according to the TNM staging system of the American Joint Committee on Cancer (AJCC), 8th edition. We also recorded whether patients received any form of adjunct chemotherapy. The overall survival (OS) was calculated from the date of surgical resection to the date of death or the last follow-up. The last follow-up time was August 2020.

\section{Statistical methods}

Descriptive statistics were described as frequencies and percentages for categorical variables and as medians with interquartile ranges for continuous variables. Normality was examined using the Shapiro-Wilk test. Baseline characteristics were compared using Pearson Chisquared test and Kruskal-Wallis rank-sum test. Preoperative biomarkers were dichotomized around their 
median or dichotomized according to their clinical references in the model. Survival curves were plotted according to the Kaplan-Meier method from the time of surgery to the time of death or last follow-up and were compared using the log-rank test. The Cox proportional hazard regression model was used for univariate and multivariate analyses. The significant statistical variables $(\mathrm{p}<0.05)$ in univariate analysis were included into the multivariate analysis to identify the independent prognostic factors for survival. The forest plot was performed to show the outcome of subgroup analysis. Interactions between subgroups were calculated based on an additive model to investigate whether the effect of D-dimer on clinical outcome was modified by other variables. Additionally, the prognostic accuracy and discriminatory ability of each prognostic model were evaluated by the concordance index (C-index) and Akaike information criterion (AIC), respectively. All analyses were performed using Stata (Stata Corporation, version 15, College Station, TX, USA), with $\mathrm{p}<0.05$ (two-sided) considered statistically significant.

\section{Results}

\section{Patients characteristics}

A total of 1351 patients with PDAC undergoing radical resection were included in this study. The final study population comprised 503 (37.23\%) women and $848(62.77 \%)$ men, with a median age of $63(58-69)$ years. Overall, $475(35.16 \%)$ patients had stage I disease, 459 (33.97\%) had stage II disease, and 417 (30.87\%) had stage III disease. Minimally invasive robotic pancreatic surgeries were performed in 312 (23.09\%) patients. Symptomatic DVT was observed in only 3 patients during hospitalization. Further information is described in Supplementary Table 1. The median follow-up time was 43.7 months; the median OS for the entire cohort was 19.0 months and 1024 (75.70\%) patients died during the follow-up period. The OS rates at 1,2 , and 3 years were $69.9 \%, 40.8 \%$, and $26.2 \%$, respectively.

Elevated preoperative plasma D-dimer levels were found in 417 (30.9\%) patients. The elevated D-dimer levels were not significantly related with increased postoperative bleeding complications when compared to the normal D-dimer levels $(4.32 \%$ vs $3.75 \%, \mathrm{p}=$ 0.619 ). The analysis of the relationship between $D$ dimer and other clinicopathologic factors is shown in Table 1. Elevated D-dimer levels were significantly associated with a high platelet level $(p=0.002)$, a low albumin level $(\mathrm{p}<0.001)$, a high NLR level, a high CA19-9 level $(\mathrm{p}=0.005)$, pancreatic head cancer $(\mathrm{p}=$ $0.012)$, poor tumor differentiation $(\mathrm{p}=0.014)$, and less adjuvant chemotherapy ( $<0.002)$.

\section{Preoperative plasma D-dimer as an independent} prognostic factor

In the univariate analysis, elevated D-dimer levels were found to be an adverse prognostic factor for OS (hazard ratio (HR) 1.47, 95\% confidence interval (CI) 1.29-1.67, $\mathrm{p}<0.001$, Table 2). Figure 1 shows the associated Kaplan-Meier curves for D-dimer in relation to overall survival for the whole cohort. The median OS of patients with elevated D-dimer levels was 6.3 months shorter than that of patients with normal D-dimer levels (15.0 months vs 21.3 months, $\mathrm{p}<0.001)$. In the multivariate analysis, preoperative plasma D-dimer was identified as an independent prognostic factor (HR 1.33, 95\% CI 1.17$1.51, \mathrm{P}<0.001$, Table 2). In addition, a high NLR, a high CA19-9 level, nerve plexus invasion, R1 resection, T3T4 stage, N1-N2 stage, poor differentiation, and adjuvant therapy were also independent predictive factors for OS.

\section{Prognostic value of D-dimer in different subgroups}

In the different surgical approach groups, patients with elevated D-dimer levels showed worse OS in both open surgery group and the robotic group (both: $p<0.001$; Fig. 2). And D-dimer remained an independent prognostic factor for OS even after adjustment for other prognostic factors (open surgery: HR 1.25, 95\% CI 1.09-1.45, $\mathrm{p}=0.008$; robotic surgery: HR 1.77, 95\% CI 1.29-2.44, p $<0001$; Supplementary Table 2).

To further investigate whether D-dimer remained a prognostic factor in certain patient subgroups, subgroups analysis was then performed (Fig. 3). Forest plot demonstrated that D-dimer was an independent reliable indicator for OS. However, no significant difference in OS was found in patients with $\mathrm{R} 1$ resection $(\mathrm{p}=0.174)$.

\section{Combination of D-dimer and other preoperative biomarkers enhances prognostic accuracy before operation}

Multivariate analysis revealed preoperative parameters, including D-dimer, CA19-9, and NLR, were independent prognostic factors for overall survival in resected PDAC patients. We therefore compared the prognostic value of these parameters and combined them to generate a more accurate prognostic model (Table 3). The C-index of the combination of CA19-9 and NLR was 0.557 and the corresponding AIC value was 13322.06. When combining all three preoperative parameters, the C-index was 0.582 , and the corresponding AIC values were 13293.50. Thus, combination of D-dimer, CA19-9, and NLR can enhance the prognostic accuracy for OS before operation.

\section{Discussion}

The prognosis of pancreatic cancer patients stays dismal regardless of the rapid progression of surgical techniques 
Table 1 Correlations between D-dimer and clinicopathologic features of patients

\begin{tabular}{|c|c|c|c|}
\hline & $\begin{array}{l}\text { D-dimer }<0.55 \mathrm{ng} / \mathrm{mL} \\
(\mathrm{n}=934)\end{array}$ & $\begin{array}{l}\text { D-dimer } \geq 0.55 \mathrm{ng} / \mathrm{mL} \\
(\mathrm{n}=417)\end{array}$ & $p$ \\
\hline Age & $63(58-69)$ & $64(58-70)$ & 0.153 \\
\hline Sex (male) & 585 (62.63\%) & $263(63.07 \%)$ & 0.878 \\
\hline BMl, $\mathrm{kg} / \mathrm{m}^{2}$ & $22.7(20.8-24.4)$ & $22.7(20.3-24.5)$ & 0.467 \\
\hline Platelet, $\times 10^{9}$ & $183(148-225)$ & $192(153-247)$ & 0.002 \\
\hline Albumin, $g / L$ & $39(36-42)$ & $39(36-41)$ & 0.089 \\
\hline Obstructive jaundice & 301 (32.23\%) & $180(43.17 \%)$ & $<0.001$ \\
\hline NLR & $2.45(1.87-3.28)$ & $2.71(2.03-3.76)$ & 0.001 \\
\hline CA19-9, U/mL & $137.3(37.3-387.2)$ & $179.2(49.0-611.4)$ & 0.005 \\
\hline ASA score & & & 0.915 \\
\hline 1 & $412(44.11 \%)$ & $184(44.12 \%)$ & \\
\hline 2 & 505 (54.07\%) & 224 (53.72\%) & \\
\hline 3 & $17(1.82 \%)$ & $9(2.16 \%)$ & \\
\hline \multicolumn{4}{|l|}{ Comorbidity } \\
\hline Hypertension & 343 (36.72\%) & 172 (41.25\%) & 0.114 \\
\hline Diabetes mellitus & 235 (25.16\%) & 85 (20.38\%) & 0.056 \\
\hline Cardiac disease & 65 (6.96\%) & $23(5.52 \%)$ & 0.321 \\
\hline Tumor location & & & 0.012 \\
\hline Head & $572(61.24 \%)$ & 285 (68.35\%) & \\
\hline Body/tail & $362(38.76 \%)$ & $132(31.65 \%)$ & \\
\hline Surgical approach & & & 0.086 \\
\hline Open & 706 (75.59\%) & 333 (79.86\%) & \\
\hline Robotic & 228 (24.41\%) & $84(20.14 \%)$ & \\
\hline Major vessel resection & $136(14.56 \%)$ & $55(13.19 \%)$ & 0.504 \\
\hline Neural invasion & 798 (85.44\%) & 357 (85.61\%) & 0.934 \\
\hline $\mathrm{R} 1$ resection, $\leq 1 \mathrm{~mm}$ & $114(12.21 \%)$ & $64(15.35 \%)$ & 0.115 \\
\hline T stage & & & $0.674^{a}$ \\
\hline $\mathrm{T} 1$ & $159(17.02 \%)$ & $64(15.35 \%)$ & \\
\hline $\mathrm{T} 2$ & 428 (45.82\%) & 192 (46.04\%) & \\
\hline T3 & $120(12.85 \%)$ & $66(15.83 \%)$ & \\
\hline $\mathrm{T} 4$ & 227 (24.30\%) & $95(22.78 \%)$ & \\
\hline N stage & & & $0.521^{a}$ \\
\hline No & 487 (52.14\%) & $218(52.28 \%)$ & \\
\hline N1 & $360(38.54 \%)$ & $142(34.05 \%)$ & \\
\hline N2 & 87 (9.31\%) & $57(13.67 \%)$ & \\
\hline Differentiation & & & $0.014^{a}$ \\
\hline Well & 361 (38.65\%) & 137 (32.85\%) & \\
\hline Moderate & $422(45.18 \%)$ & $193(46.28 \%)$ & \\
\hline Poor & $151(16.17 \%)$ & $87(20.86 \%)$ & \\
\hline Adjuvant chemotherapy & $556(59.53 \%)$ & $210(50.34 \%)$ & 0.002 \\
\hline
\end{tabular}

$B M I$, body mass index; NLR, neutrophil lymphocyte ratio; CA19-9, serum carbohydrate antigen 19-9 $p$ value $<0.05$ indicates statistical significance (in bold)

${ }^{a}$ The chi-squared test for trend was used for the comparison of ordinal variables 
Table 2 Univariate and multivariate Cox proportional-hazard regression analysis for overall survival in PDAC patients undergoing resection

\begin{tabular}{|c|c|c|c|c|c|}
\hline & \multirow[t]{2}{*}{ Patients (\%) } & \multicolumn{2}{|c|}{ Univariable analysis } & \multicolumn{2}{|c|}{ Multivariable analysis } \\
\hline & & Hazard ratio & $p$ & Hazard ratio & $p$ \\
\hline Age, $\geq 65$ & $591(43.75 \%)$ & $1.23(1.09-1.38)$ & 0.001 & $1.13(1.00-1.29)$ & 0.057 \\
\hline Sex (male) & 848 (62.77\%) & $1.05(0.92-1.19)$ & 0.468 & & \\
\hline Platelets, $\geq 200 \times 10^{9}$ & $561(41.52 \%)$ & $1.10(0.98-1.25)$ & 0.110 & & \\
\hline$N L R, \geq 3$ & 470 (34.79\%) & $1.28(1.12-1.45)$ & $<0.001$ & $1.19(1.05-1.36)$ & 0.009 \\
\hline Albumin, < 40 g/L & 742 (54.92\%) & $1.19(1.05-1.34)$ & 0.007 & $1.11(0.98-1.26)$ & 0.116 \\
\hline Obstructive jaundice & 481 (35.60\%) & $1.16(1.02-1.31)$ & 0.025 & $0.94(0.81-1.09)$ & 0.424 \\
\hline D-dimer, $\geq 0.55 \mathrm{ng} / \mathrm{mL}$ & 417 (30.87\%) & $1.47(1.29-1.67)$ & $<0.001$ & $1.33(1.17-1.51)$ & $<0.001$ \\
\hline CA19-9, $\geq 37 \mathrm{U} / \mathrm{mL}$ & $1036(76.68 \%)$ & $1.40(1.23-1.58)$ & $<0.001$ & $1.25(1.10-1.41)$ & 0.001 \\
\hline \multicolumn{6}{|l|}{ Tumor location } \\
\hline Head & 857 (63.43\%) & Ref. & & & \\
\hline Body/tail & 494 (36.57\%) & $0.97(0.85-1.10)$ & 0.639 & & \\
\hline Major vessel resection & 191 (14.14\%) & $1.57(1.33-1.86)$ & $<0.001$ & $1.08(0.89-1.32)$ & 0.419 \\
\hline Neural invasion & 1155 (85.49\%) & $1.51(1.26-1.81)$ & $<0.001$ & $1.39(1.15-1.67)$ & 0.001 \\
\hline $\mathrm{R} 1$ resection, $\leq 1 \mathrm{~mm}$ & $178(13.18 \%)$ & $1.51(1.27-1.79)$ & $<0.001$ & $1.39(1.16-1.65)$ & $<0.001$ \\
\hline \multicolumn{6}{|l|}{ T stage } \\
\hline $\mathrm{T} 1-\mathrm{T} 2$ & $843(62.40 \%)$ & Ref. & & Ref. & \\
\hline T3-T4 & $508(37.60 \%)$ & $1.57(1.39-1.78)$ & $<0.001$ & $1.54(1.34-1.80)$ & $<0.001$ \\
\hline \multicolumn{6}{|l|}{ N stage } \\
\hline NO & 705 (52.18\%) & Ref. & & Ref. & \\
\hline N1-N2 & $646(47.82 \%)$ & $1.58(1.40-1.79)$ & $<0.001$ & $1.49(1.31-1.69)$ & $<0.001$ \\
\hline \multicolumn{6}{|l|}{ Differentiation } \\
\hline Well-moderate & 1113 (82.38\%) & Ref. & & Ref. & \\
\hline Poor & 238 (17.62\%) & $1.77(1.52-2.06)$ & $<0.001$ & $1.73(1.48-2.02)$ & $<0.001$ \\
\hline Adjuvant therapy & 751 (55.59\%) & $0.61(0.54-0.69)$ & $<0.001$ & $0.61(0.54-0.70)$ & $<0.001$ \\
\hline
\end{tabular}

$P D A C$, pancreatic ductal adenocarcinoma; NLR, neutrophil lymphocyte ratio; CA19-9, serum carbohydrate antigen 19-9 $p$ value $<0.05$ indicates statistical significance (in bold)

and adjuvant therapies. Increasing evidence suggests that not only the intrinsic histopathologic features of the tumor but also the host-related factors are associated with long-term disease outcomes [23-25]. According to new clinical guidelines, considering the special biological behavior of pancreatic cancer, plasma biomarkers and conditional host-related factors are playing more important roles in the decision-making process [23]. In malignancy, together with the host cell inflammatory, cancer cell-specific prothrombotic properties induce the hypercoagulation state [26]. As a consequence, a subclinical activation of blood coagulation is prevalent in cancer patients, as demonstrated by abnormalities of coagulation biomarkers. As a stable fibrin degradation product, plasma D-dimer is a marker of hypercoagulation and is usually used for the assessment of suspected thrombosis or disseminated intravascular coagulation (DIC) in clinical practice [15]. In the present study, preoperative plasma D-dimer was elevated in $30.9 \%$ of resectable
PDAC patients, and the elevated levels were found to be significantly related to poor prognosis in patients following radical pancreatic surgery.

The D-dimer showed a reliable prognostic value in pancreatic cancer, regardless of age, NLR levels, obstructive jaundice, CA19-9 levels, pathologic staging, poor differentiation, and adjuvant therapy. However, Ddimer is not an accurate prognostic indicator for patients with R1 resection. Several possible reasons might account for it. First, patients with R1 resection are more likely to develop local recurrence when compared to patients with R0 resection, which would negatively affect the prognosis independently [27]. Second, there are only $13.18 \%$ of patient with $\mathrm{R} 1$ resection, and no statistically significant association was found between $\mathrm{D}$-dimer and $\mathrm{R} 1$ resection $(\mathrm{p}=0.383)$. More patients are needed to improve the statistical power.

Previous studies also demonstrated the utility of Ddimer as a prognostic marker in pancreatic cancer. It 


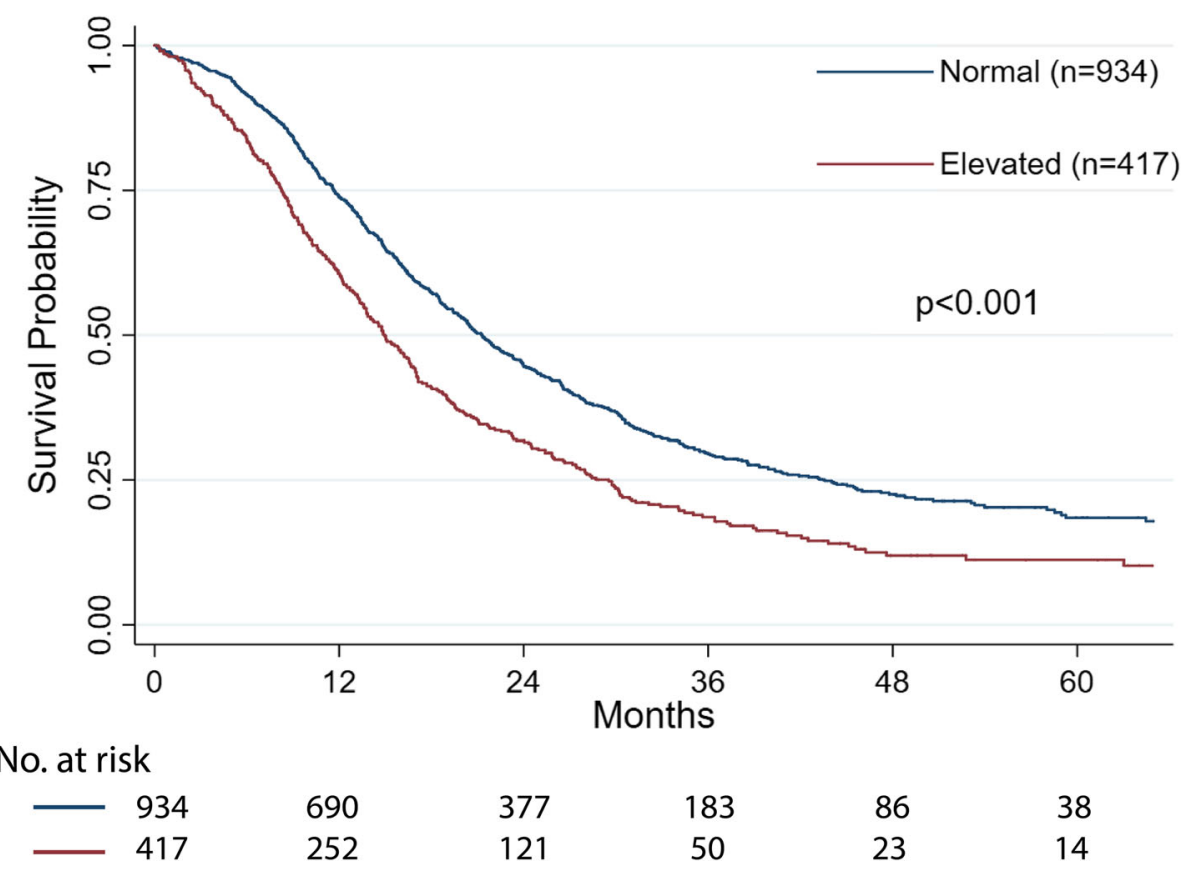

Fig. 1 Kaplan-Meier survival curve of overall survival according to preoperative plasma D-dimer level in PDAC patients

has been reported that patients with high levels of preoperative plasma D-dimer are at high risk for locally advanced disease or occult hepatic metastases [18]. Subsequent studies have also reported that plasma Ddimer serves as a negative prognostic factor in pancreatic cancer, but the clinical significance remains controversial because of the small number of patients analyzed and the limited perioperative factors included in these studies [19, 28-30]. In addition, Cao et al. [19] examined the prognostic value of preoperative plasma $\mathrm{D}$-dimer in operable pancreatic cancer patients, but the results in this study were not adjusted by other risk factors, and the scale of the study was limited. In a Japanese cohort, Watanabe et al. [20] found that the D-dimer was the only independent prognostic factor in resectable pancreatic cancer. Furthermore, Durczynski et al. [31] found that the D-dimer levels in portal blood were related with poorer overall survival in pancreatic cancer.

However, the mechanism underlying the association between the plasma D-dimer and the prognosis of pancreatic cancer remains unclear. Recent studies have demonstrated the bidirectional association between

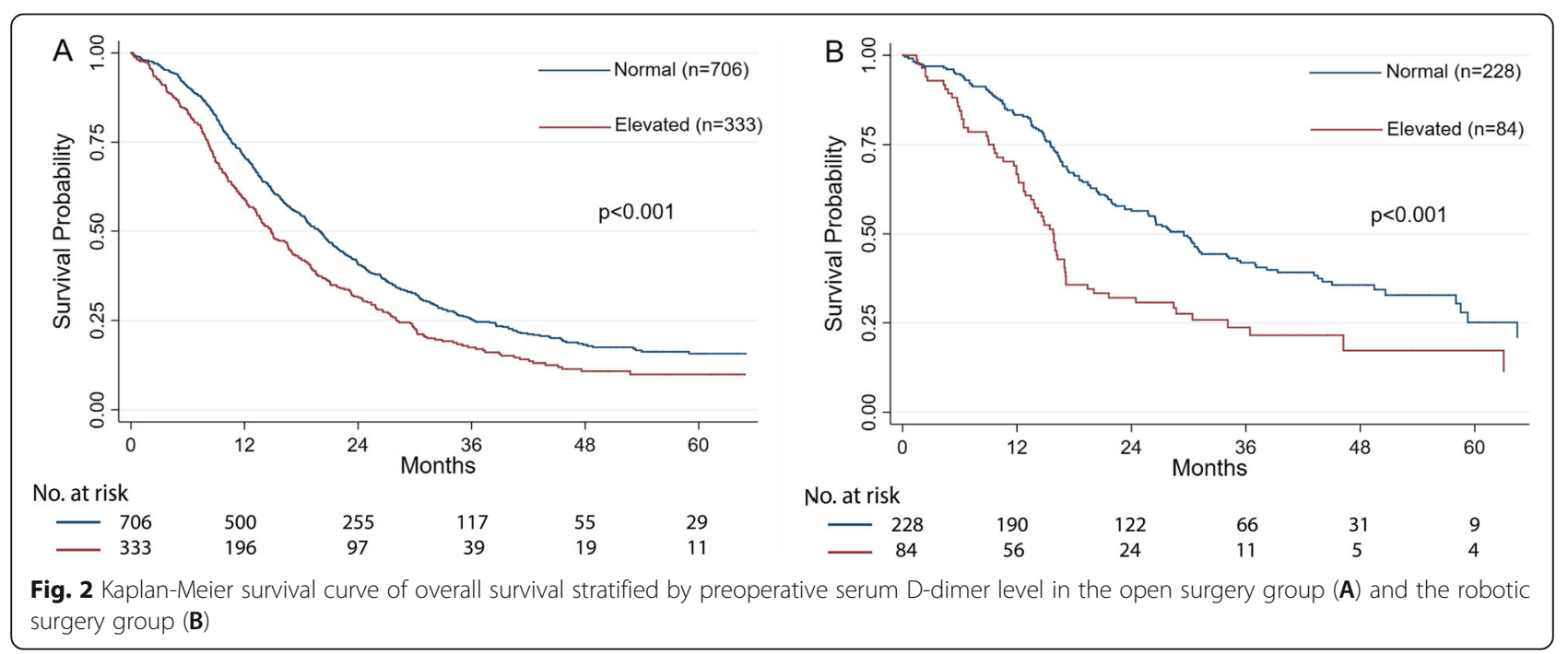




\begin{tabular}{|c|c|c|c|c|}
\hline \multicolumn{2}{|c|}{ Normal vs. Elevated } & \multirow{2}{*}{$\begin{array}{l}\text { HR }(95 \% \mathrm{CI}) \\
1.47(1.29,1.67)\end{array}$} & \multirow{2}{*}{$\begin{array}{l}\mathrm{p}_{\mathrm{HR}} \\
<0.001\end{array}$} & \multirow[t]{2}{*}{$\mathrm{p}_{\text {interaction }}$} \\
\hline Overall & $\longmapsto$ & & & \\
\hline $\begin{array}{l}\text { Age } \\
<65 \mathrm{yr} \\
\geq 65 \mathrm{yr}\end{array}$ & $\longmapsto$ & $\begin{array}{l}1.40(1.17,1.69) \\
1.47(1.22,1.77)\end{array}$ & $\begin{array}{l}<0.001 \\
<0.001\end{array}$ & .601 \\
\hline $\begin{array}{l}\text { NLR } \\
<3 \\
\geq 3\end{array}$ & $\longmapsto$ & $\begin{array}{l}1.41(1.20,1.67) \\
1.52(1.23,1.87)\end{array}$ & $\begin{array}{l}0.007 \\
<0.001\end{array}$ & .531 \\
\hline $\begin{array}{l}\text { Obstructive janudice } \\
\text { Yes } \\
\text { No }\end{array}$ & $\longmapsto$ & $\begin{array}{l}1.38(1.13,1.69) \\
1.50(1.27,1.78)\end{array}$ & $\begin{array}{l}0.002 \\
<0.001\end{array}$ & .493 \\
\hline $\begin{array}{l}\text { CA19-9 } \\
<37 \mathrm{U} / \mathrm{mL} \\
\geq 37 \mathrm{U} / \mathrm{mL}\end{array}$ & $\longmapsto$ & $\begin{array}{l}1.44(1.18,1.75) \\
1.43(1.20,1.70)\end{array}$ & $\begin{array}{l}<0.001 \\
<0.001\end{array}$ & .999 \\
\hline $\begin{array}{l}\text { Neural invasion } \\
\text { Present } \\
\text { Absent }\end{array}$ & $\longmapsto$ & $\begin{array}{l}1.44(1.25,1.65) \\
1.66(1.17,2.37)\end{array}$ & $\begin{array}{l}<0.001 \\
<0.001\end{array}$ & .485 \\
\hline $\begin{array}{l}\text { R1 resection } \\
\leq 1 \mathrm{~mm} \\
>1 \mathrm{~mm}\end{array}$ & $\longmapsto$ & $\begin{array}{l}1.26(0.90,1.75) \\
1.48(1.29,1.71)\end{array}$ & $\begin{array}{l}0.174 \\
<0.001\end{array}$ & .383 \\
\hline $\begin{array}{l}\text { T stage } \\
\text { T1-T2 } \\
\text { T3-T4 }\end{array}$ & $\longmapsto$ & $\begin{array}{l}1.60(1.35,1.90) \\
1.29(1.05,1.58)\end{array}$ & $\begin{array}{l}<0.001 \\
0.014\end{array}$ & .119 \\
\hline $\begin{array}{l}\text { N stage } \\
\text { N0 } \\
\text { N1-N2 }\end{array}$ & $\longmapsto$ & $\begin{array}{l}1.59(1.32,1.91) \\
1.39(1.16,1.67)\end{array}$ & $\begin{array}{l}<0.001 \\
<0.001\end{array}$ & .263 \\
\hline $\begin{array}{l}\text { Differentiation } \\
\text { Well-moderate } \\
\text { Poor }\end{array}$ & $\longmapsto$ & $\begin{array}{l}1.45(1.26,1.68) \\
1.40(1.06,1.85)\end{array}$ & $\begin{array}{l}<0.001 \\
0.019\end{array}$ & .997 \\
\hline $\begin{array}{l}\text { Adjuvant therapy } \\
\text { With } \\
\text { Without }\end{array}$ & $\longmapsto$ & $\begin{array}{l}1.42(1.18,1.72) \\
1.36(1.14,1.64)\end{array}$ & $\begin{array}{l}<0.001 \\
0.001\end{array}$ & .781 \\
\hline
\end{tabular}

Fig. 3 Relationship between the D-dimer and overall survival. HR plots of overall survival rate according to the D-dimer levels are shown for the total cohort. HR, hazard ratio; Cl, confidence interval; NLR, neutrophil lymphocyte ratio; CA19-9, serum carbohydrate antigen 19-9

Table 3 Prognostic value of preoperative parameters for PDAC patients receiving radical surgery

\begin{tabular}{lllll}
\hline & \multicolumn{2}{c}{ Concordance index } & AIC & \multicolumn{1}{c}{$\begin{array}{l}\text { Likelihood } \\
\text { ratio X }\end{array}$} \\
\cline { 2 - 5 } & C-index & Bootstrap 95\% Cl & 13322.60 & 34.26 \\
D-dimer & 0.551 & $0.537-0.565$ & 13328.66 & 28.21 \\
CA19-9 & 0.543 & $0.529-0.558$ & 13343.06 & 13.81 \\
NLR & 0.528 & $0.514-0.542$ & 13322.06 & 36.80 \\
CA19-9+ NLR & 0.557 & $0.541-0.574$ & 13300.78 & 58.50 \\
D-dimer+ CA19-9 & 0.575 & $0.559-0.591$ & 13293.50 & 67.36 \\
D-dimer+ CA19-9+ NLR & 0.582 & $0.566-0.598$ & & \\
\hline
\end{tabular}

PDAC, pancreatic ductal adenocarcinoma; AIC, Akaike information criterion; C-index, concordance index; $C l$, confidence interval; CA19-9, carbohydrate antigen 19-9; $N L R$, neutrophil lymphocyte ratio 
coagulation and cancer, and cancer-related hypercoagulation is reported to be closely related to cancer progression [12, 32]. Multiple and interdependent processes between the tumor and the patient induce a hypercoagulable state, including tumor-procoagulant activity, host inflammatory responses, and cancer treatments [12]. Tissue factor (TF) is the main initiator of the coagulation cascade, which is highly expressed due to cancer [33]. In addition, in malignancy, TF is also overexpressed by host normal blood cells triggered by cancer-derived inflammatory stimuli [26]. Our studies also found that D-dimer correlated with NLR, an inflammatory indicator, suggesting the relationship between host inflammatory responses and cancer-related hypercoagulation.

On the other hand, some evidence suggested that hypercoagulable state can contribute to cancer progression in turn [32]. TF expression in cancer is related with a variety of pathologic processes, such as thrombosis, metastasis, tumor angiogenesis, and tumor growth [34]. The mesh of fibrin, induced by TF surface expression, was found to envelop cancer cells preventing them from being recognized by NK cells. Furthermore, the formation of platelet-fibrin rich microemboli could help tumor cells escape NKmediated immune recognition [35]. In vitro experiments, inhibition of TF, FXa, or thrombin has been shown to prevent the formation of metastasis in melanoma tumors [36]. Besides that, a growing body of evidence has suggested that anticoagulants have antitumor effects and can increase the survival time in solid tumor patients [37-40]. Klerk et al. reported that combining low-molecular-weight heparin (LMWH) with other adjuvant therapies improved prognosis in patients with advanced malignancy [38]. In advanced pancreatic cancer patients, the addition of LMWH to gemcitabine-based chemotherapy significantly improved the response and survival [41]. These findings regarding coagulation and cancer supported a pathological role for procoagulant activity in cancer. However, further studies associated with the antitumor effects of anticoagulants are needed in the operable pancreatic cancer patients, especially in patients with elevated D-dimer levels.

Some limitations in this study also warrant emphasis. First, because this was a retrospective study, the use of postoperative prophylactic anticoagulant therapy was not available in the database. Second, patients with neoadjuvant therapy or preoperative anticoagulation treatment were excluded, which may limit the generalizability of this study. Third, the kinetic of serum D-dimer were not analyzed in this study. Further studies are needed to identify the prognostic implications of the kinetic of D-dimer [42].

\section{Conclusions}

Here, we presented one of the largest studies on the prognostic value of different preoperative biomarkers, and found that preoperative plasma D-dimer is an independent indicator for PDAC patients after radical surgery. D-dimer appears to be a promising and reliable indicator for improving the prognostication of patients with pancreatic cancer before surgery. Combination of D-dimer, CA19-9, and NLR can further improve the prognostic accuracy before operation for PDAC patients. These findings also emphasize the importance of coagulation biomarkers and the role of the coagulation system in pancreatic cancer.

\section{Abbreviations}

PDAC: Pancreatic ductal adenocarcinoma; OS: Overall survival; DVT: Deep venous thrombosis; PE: Pulmonary embolism; DIC: Disseminated intravascular coagulation; BMI: Body mass index; NLR: Neutrophil lymphocyte ratio; CA199: Carbohydrate antigen 19-9; AJCC: American Joint Committee on Cancer; C-index: Concordance index; AIC: Akaike information criterion; Cl: Confidence interval

\section{Supplementary Information}

The online version contains supplementary material available at https://doi. org/10.1186/s12957-021-02281-8.

Additional file 1: Supplementary Table 1. Baseline characteristics.

Additional file 2: Supplementary Table 2. Multivariate Cox

proportional-hazard regression analysis for overall survival in the open surgery group and robotic surgery group.

\section{Acknowledgements}

Not applicable

Authors' contributions

HDC, FL, SZ: data curation, statistical analysis, data interpretation, methodology, original draft; JX, JZ, XD: data curation, review and editing; HC: validation, conceptualization, review and editing; BS: supervision, conceptualization, funding acquisition. All authors read and approved the final manuscript.

\section{Funding}

This work was supported by National Nature Science Foundation of China (No. 81871906)

\section{Availability of data and materials}

The datasets used and analyzed during the present study are available from the corresponding author on reasonable request.

\section{Declarations}

Ethics approval and consent to participate

This study was approved by the review board of Shanghai Ruijin Hospital (No. 2020-361). Informed consent was waived according the committee's regulations.

Consent for publication

Not applicable

\section{Competing interests}

The authors declare that they have no competing interests.

Received: 8 March 2021 Accepted: 31 May 2021

Published online: 09 June 2021

References

1. Siegel RL, Miller KD, Jemal A. Cancer statistics, 2020. CA Cancer J Clin. 2020; 70(1):7-30. https://doi.org/10.3322/caac.21590. 
2. Kamisawa T, Wood LD, Itoi T, Takaori K. Pancreatic cancer. Lancet. 2016; 388(10039):73-85. https://doi.org/10.1016/S0140-6736(16)00141-0.

3. Liu L, Xu H, Wang W, Wu C, Chen Y, Yang J, et al. A preoperative serum signature of CEA+/CA125+/CA19-9 >/= $1000 \mathrm{U} / \mathrm{mL}$ indicates poor outcome to pancreatectomy for pancreatic cancer. Int J Cancer. 2015;136(9):2216-27. https://doi.org/10.1002/ijc.29242.

4. Aziz MH, Sideras K, Aziz NA, Mauff K, Haen R, Roos D, et al. The systemicimmune-inflammation index independently predicts survival and recurrence in resectable pancreatic cancer and its prognostic value depends on bilirubin levels: a retrospective multicenter cohort study. Ann Surg. 2019: 270(1):139-46. https://doi.org/10.1097/SLA.0000000000002660.

5. Pour PM, Tempero MM, Takasaki H, Uchida E, Takiyama Y, Burnett DA, et al. Expression of blood group-related antigens $\mathrm{ABH}$, Lewis $\mathrm{A}$, Lewis $\mathrm{B}$, Lewis $\mathrm{X}$, Lewis $Y$, and CA 19-9 in pancreatic cancer cells in comparison with the patient's blood group type. Cancer Res. 1988:48(19):5422-6

6. Poruk KE, Gay DZ, Brown K, Mulvihill JD, Boucher KM, Scaife CL, et al. The clinical utility of CA 19-9 in pancreatic adenocarcinoma: diagnostic and prognostic updates. Curr Mol Med. 2013;13(3):340-51. https://doi.org/10.21 74/1566524011313030003.

7. Bunger S, Laubert T, Roblick UJ, Habermann JK. Serum biomarkers for improved diagnostic of pancreatic cancer: a current overview. J Cancer Res Clin Oncol. 2011;137(3):375-89. https://doi.org/10.1007/s00432-010-0965-x.

8. Li J, Li Z, Kan H, Sun Z, Xing J, Cheng Y, et al. CA19-9 elevation as an indication to start salvage treatment in surveillance after pancreatic cancer resection. Pancreatology. 2019;19(2):302-6. https://doi.org/10.1016/j.pan.201 9.01.023.

9. Tsai S, George B, Wittmann D, Ritch PS, Krepline AN, Aldakkak M, et al. Importance of normalization of CA19-9 levels following neoadjuvant therapy in patients with localized pancreatic cancer. Ann Surg. 2020;271(4): 740-7. https://doi.org/10.1097/SLA.0000000000003049.

10. Nakano Y, Hirata Y, Shimogawara T, Yamada T, Mihara K, Nishiyama R, et al. Frailty is a useful predictive marker of postoperative complications after pancreaticoduodenectomy. World J Surg Oncol. 2020;18(1):194. https://doi. org/10.1186/s12957-020-01969-7.

11. Khorana AA, Fine RL. Pancreatic cancer and thromboembolic disease. Lancet Oncol. 2004;5(11):655-63. https://doi.org/10.1016/S1470-2045(04)01 606-7.

12. De Cicco M. The prothrombotic state in cancer: pathogenic mechanisms. Crit Rev Oncol Hematol. 2004;50(3):187-96. https://doi.org/10.1016/j. critrevonc.2003.10.003.

13. Ye L, Cai L, Fu Y, Zhuang D, Hu X, Jie Y. The prevalence, risk factors, and prognostic value of venous thromboembolism in ovarian cancer patients receiving chemotherapy: a systematic review and meta-analysis. World J Surg Oncol. 2021;19(1):12. https://doi.org/10.1186/s12957-020-02101-5.

14. Papila Kundaktepe B, Papila C. The clinical significance of preoperative plasma fibrinogen levels and platelet counts in resectable colon cancer. World I Surg Oncol. 2021;19(1):69. https://doi.org/10.1186/s12957-021-02180-y.

15. Weitz JI, Fredenburgh JC, Eikelboom JW. A test in context: D-dimer. J Am Coll Cardiol. 2017;70(19):2411-20. https://doi.org/10.1016/j.jacc.2017.09.024

16. Johnson ED, Schell JC, Rodgers GM. The D-dimer assay. Am J Hematol. 2019;94(7):833-9. https://doi.org/10.1002/ajh.25482.

17. Li W, Tang Y, Song Y, Chen SH, Sisliyan N, Ni M, et al. Prognostic role of pretreatment plasma D-dimer in patients with solid tumors: a systematic review and meta-analysis. Cell Physiol Biochem. 2018;45(4):1663-76. https:// doi.org/10.1159/000487734

18. Durczynski A, Kumor A, Hogendorf P, Szymanski D, Grzelak P, Strzelczyk J. Preoperative high level of D-dimers predicts unresectability of pancreatic head cancer. World J Gastroenterol. 2014;20(36):13167-71. https://doi.org/1 0.3748/wjg.v20.i36.13167.

19. Cao J, Fu Z, Gao L, Wang X, Cheng S, Wang X, et al. Evaluation of serum Ddimer, fibrinogen, and CA19-9 for postoperative monitoring and survival prediction in resectable pancreatic carcinoma. World J Surg Oncol. 2017; 15(1):48. https://doi.org/10.1186/s12957-017-1104-9.

20. Watanabe A, Harimoto N, Araki K, Kubo N, Igarashi T, Tsukagoshi M, et al. Ddimer could be a surrogate postoperative prognostic marker of resectable pancreatic cancer. Pancreas. 2020;49(4):e36-8. https://doi.org/10.1097/MPA. 0000000000001537.

21. Chen $H$, Wang $W$, Ying $X$, Deng $X$, Peng $C$, Cheng $D$, et al. Predictive factors for postoperative pancreatitis after pancreaticoduodenectomy: a singlecenter retrospective analysis of 1465 patients. Pancreatology. 2020;20(2): 211-6. https://doi.org/10.1016/j.pan.2019.11.014.
22. Shi Y, Wang W, Qiu W, Zhao S, Wang J, Weng Y, et al. Learning curve from 450 cases of robot-assisted pancreaticoduocectomy in a high-volume pancreatic center: optimization of operative procedure and a retrospective study. Ann Surg. 2019;Publish Ahead of Print. https://doi.org/10.1097/SLA. 0000000000003664

23. Isaji S, Mizuno S, Windsor JA, Bassi C, Fernandez-Del Castillo C, Hackert T, et al. International consensus on definition and criteria of borderline resectable pancreatic ductal adenocarcinoma 2017. Pancreatology. 2018: 18(1):2-11. https://doi.org/10.1016/j.pan.2017.11.011.

24. Li S, Xu H, Wang W, Gao H, Li H, Zhang S, et al. The systemic inflammation response index predicts survival and recurrence in patients with resectable pancreatic ductal adenocarcinoma. Cancer Manag Res. 2019;11:3327-37. https://doi.org/10.2147/CMAR.S197911.

25. Neoptolemos JP, Kleeff J, Michl P, Costello E, Greenhalf W, Palmer DH. Therapeutic developments in pancreatic cancer: current and future perspectives. Nat Rev Gastroenterol Hepatol. 2018;15(6):333-48. https://doi. org/10.1038/s41575-018-0005-x.

26. Falanga A, Schieppati F, Russo D. Cancer tissue procoagulant mechanisms and the hypercoagulable state of patients with cancer. Semin Thromb Hemost. 2015;41(7):756-64. https://doi.org/10.1055/s-0035-1564040.

27. Demir IE, Jager C, Schlitter AM, Konukiewitz B, Stecher L, Schorn S, et al. R0 versus R1 resection matters after pancreaticoduodenectomy, and less after distal or total pancreatectomy for pancreatic cancer. Ann Surg. 2018;268(6):1058-68. https://doi.org/10.1097/SLA. 0000000000002345

28. Sun W, Ren H, Gao CT, Ma WD, Luo L, Liu Y, et al. Clinical and prognostic significance of coagulation assays in pancreatic cancer patients with absence of venous thromboembolism. Am J Clin Oncol. 2015;38(6):550-6. https://doi.org/10.1097/01.coc.0000436088.69084.22.

29. Stender MT, Larsen AC, Sall M, Thorlacius-Ussing O. D-dimer predicts prognosis and non-resectability in patients with pancreatic cancer: a prospective cohort study. Blood Coagul Fibrinolysis. 2016;27(5):597601. https://doi.org/10.1097/MBC.0000000000000559.

30. Liu P, Zhu Y, Liu L. Elevated pretreatment plasma D-dimer levels and platelet counts predict poor prognosis in pancreatic adenocarcinoma. Onco Targets Ther. 2015;8:1335-40. https://doi.org/10.2147/OTT.S82329.

31. Durczynski A, Skulimowski A, Hogendorf P, Szymanski D, Kumor A, Marski K, et al. The concentration of D-dimers in portal blood positively correlates with overall survival in patients with non-resectable pancreatic cancer. World J Surg Oncol. 2017;15(1):223. https://doi.org/10.1186/s12957-017-12 91-4.

32. Mitrugno A, Tormoen GW, Kuhn P, McCarty OJ. The prothrombotic activity of cancer cells in the circulation. Blood Rev. 2016;30(1):11-9. https://doi. org/10.1016/j.blre.2015.07.001.

33. Campello E, llich A, Simioni P, Key NS. The relationship between pancreatic cancer and hypercoagulability: a comprehensive review on epidemiological and biological issues. Br J Cancer. 2019;121(5):359-71. https://doi.org/10.103 8/s41416-019-0510-x.

34. Kasthuri RS, Taubman MB, Mackman N. Role of tissue factor in cancer. J Clin Oncol. 2009;27(29):4834-8. https://doi.org/10.1200/JCO.2009.22.6324.

35. Gay LJ, Felding-Habermann B. Contribution of platelets to tumour metastasis. Nat Rev Cancer. 2011;11(2):123-34. https://doi.org/10.1038/nrc3 004.

36. van Es N, Sturk A, Middeldorp S, Nieuwland R. Effects of cancer on platelets. Semin Oncol. 2014;41(3):311-8. https://doi.org/10.1053/j.seminoncol.2014.04. 015.

37. Tieken C, Versteeg HH. Anticoagulants versus cancer. Thrombosis Research. 2016;140:S148-53. https://doi.org/10.1016/S0049-3848(16)30114-1.

38. Klerk CP, Smorenburg SM, Otten HM, Lensing AW, Prins MH, Piovella F, et al. The effect of low molecular weight heparin on survival in patients with advanced malignancy. J Clin Oncol. 2005;23(10):2130-5. https://doi.org/10.12 00/JCO.2005.03.134

39. Featherby S, Xiao YP, Ettelaie C, Nikitenko LL, Greenman J, Maraveyas A. Low molecular weight heparin and direct oral anticoagulants influence tumour formation, growth, invasion and vascularisation by separate mechanisms. Sci Rep. 2019;9(1):6272. https://doi.org/10.1038/s41598-019-42 738-1.

40. Rothwell PM, Wilson M, Elwin C-E, Norrving B, Algra A, Warlow CP, et al. Long-term effect of aspirin on colorectal cancer incidence and mortality: 20-year follow-up of five randomised trials. Lancet. 2010;376(9754):1741-50. https://doi.org/10.1016/S0140-6736(10)61543-7. 
41. Icli F, Akbulut H, Utkan G, Yalcin B, Dincol D, Isikdogan A, et al. Low molecular weight heparin (LMWH) increases the efficacy of cisplatinum plus gemcitabine combination in advanced pancreatic cancer. J Surg Oncol. 2007;95(6):507-12. https://doi.org/10.1002/jso.20728.

42. Shultz DB, Chan C, Shaffer JL, Kunz PL, Koong AC, Chang DT. Postradiotherapy CA19-9 kinetics correlate with outcomes in patients with pancreatic adenocarcinoma. Pancreas. 2014;43(5):777-83. https://doi.org/1 0.1097/MPA.0000000000000098.

\section{Publisher's Note}

Springer Nature remains neutral with regard to jurisdictional claims in published maps and institutional affiliations.

Ready to submit your research? Choose BMC and benefit from:

- fast, convenient online submission

- thorough peer review by experienced researchers in your field

- rapid publication on acceptance

- support for research data, including large and complex data types

- gold Open Access which fosters wider collaboration and increased citations

- maximum visibility for your research: over $100 \mathrm{M}$ website views per year

At $\mathrm{BMC}$, research is always in progress.

Learn more biomedcentral.com/submissions 